\title{
Effect of Artificial LED on the Growth, Anthocyanin, Chlorophyll and Total Phenolic Content of Buckwheat Seedling
}

\author{
Md Obyedul Kalam Azad ${ }^{1,2}$, Md Adnan ${ }^{1,3}$, Jimin Son ${ }^{1}$, Dong Ha Cho ${ }^{1}$ and Cheol Ho Park ${ }^{* 1}$ \\ ${ }^{1}$ College of Biomedical Science, Korea \\ ${ }^{2}$ Head of Research and Technology, Korea \\ ${ }^{3}$ Senior Researcher, Korea
}

Received: 䟧January 09, 2019; Published: 濫January 31, 2019

*Corresponding author: Cheol Ho Park, College of Biomedical Science, Chuncheon, 24341, Korea

\begin{abstract}
Artificial light emitting diode (LED) light was applied to enhance the growth characteristics and phenolic compounds of buckwheat (Fagopyrum esculentum) seedlings. The wavelength of the LED lights was blue $470 \mathrm{~nm}$, red $660 \mathrm{~nm}$, blue + red (BR 1:1) and far-red 740nm. The LED light was applied for 15 days after the emergence of two true leaves and a control experiment was done without supplemental light. In this study, it is shown that BR light significantly increased plant growth such as plant height, node number, leaf number and plant fresh weight compared to control. In the same way, the phenolic compounds content including ascorbic acid $(249 \mathrm{mg} / 100 \mathrm{~g})$, anthocyanin $(686 \mathrm{mg} / 100 \mathrm{~g})$, total chlorophyll $(3.0 \mathrm{mg} / 100 \mathrm{~g})$, total phenolic $(782 \mathrm{mg} / 100 \mathrm{~g})$ contents of buckwheat seedling were significantly increased under BR light compared to control $(100 \mathrm{mg} / 100 \mathrm{~g}$; $210 \mathrm{mg} / 100 \mathrm{~g} ; 2.1 \mathrm{mg} / 100 \mathrm{~g} ; 490 \mathrm{mg} / 100 \mathrm{~g}$, respectively).
\end{abstract}

Keywords: Ascorbic Acid; Anthocyanin; Buckwheat; Chlorophyll; LED Light; Phenolic Compounds

Abbreviations: LED: Light-Emitting Diode; B+R: Blue + Red; R: Red; B: Blue; FR: Far-Red; RH: Relative Humidity; DMRT: Duncan's Multiple Range Test; GAE: Gallic Acid Equivalent; PAL: Phenylalanine Ammonia-Lyase; CHS: Chalcone Synthesis; DFR: Dihydroflavonol-4-Reductase

\section{Introduction}

Sunlight is one of the most important factors for plant growth and development. However, in the glasshouse, sometimes the intensity of sunlight is not enough for plants to grow well because of continuous overcast, rainy days, greenhouse structures and coverings [1]. Artificial LED light has been strategically used to improve the plant food quality especially phenolic compounds contents in a controlled environment [2]. It is in many reports that blue and red light are vital wavelengths for plant growth and development [3]. The absorption percentage of blue and red light is about $90 \%$ than the other spectra [4]. Light is the basic factor for growth and development of plant [5]. Supplemental light stimulates plant growth, promote stem extension [6], and increase a dry matter of pepper [5] radish and lettuce [7] and increase the leaf number of Alternanthera brasiliana [8]. Researchers found that light quality affects the phytochemical content of plants $[9,10]$. It has been reported that blue light increased anthocyanin in tomato [11], carotenoids in coffee [12] and ascorbic acid in lettuce plants.
On the other hand, observed that lower red / far-red ratio (R / FR), or more FR relative to $\mathrm{R}$ light decreased anthocyanin concentrations in potato and alpine crops [13]. These results have shown the viability of optimizing light quality in increasing phytochemical concentration and growth of plants. The aim of this work was to determine which wavelengths of the supplemental light emitting diodes (LEDs) work best for buckwheat plants to obtain highquality vegetables with enriched phytochemical concentrations in glass house condition.

\section{Materials and Methods}

Buckwheat seeds were sown in a plastic tray and placed in a growth chamber maintaining temperature $250 \mathrm{C}$ and $\mathrm{RH} 50 \%$. After germination ( 3 days after seeding) all trays were moved to the greenhouse and waited up to distinct two true leaves. Then two trays were subjected to each supplemental light treatment (as described below) inside the greenhouse. 


\section{Supplemental Light Treatments}

A LED light panel consists of 20 LED sticks (20 LED bulbs on a stick) with the main controller $(33.5 \mathrm{~cm}$ wide, $27.5 \mathrm{~cm}$ long and $10 \mathrm{~cm}$ height, LPRS Series, Good Feeling Co. Ltd., Korea). LEDs light were placed horizontally $25 \mathrm{~cm}$ above the plant canopy. The experiments composed of five treatments with different supplementary LED wavelengths: red (R) 660nm, blue (B) 470nm, far-red (FR) 740nm, a combination of blue and red light (B: R 1:1), and natural light treatment (without any supplementary lighting) as a control. Supplemental light duration was $16 \mathrm{~h} /$ day (5am to $9 \mathrm{pm}$ ).

\section{Measurements}

Data were collected (after 15 days of providing supplemental light) to measure the growth characteristics such as plant height, stem length, no. of node and leaf, leaf length, leaf width, and plant fresh weight. After growth measurements, the samples were freezedried and prepared for chemical analysis.

\section{Determination of Ascorbic Acid}

A modified protocol reported by Gahler et al. [14]. was used to determine the content of ascorbic acid. Fresh samples (10g) were mixed with $40 \mathrm{~mL}$ of $5 \%$ Metaphosphoric acid and blended to extract ascorbic acid. The mixtures were shaken at $250 \mathrm{rpm}$ for 5 minutes and then centrifuged at $3,000 \times \mathrm{g}$ for $10 \mathrm{~min}$. The supernatants were used to determine the concentration of ascorbic acid using the HPLC system equipped with a C18 column (Agilent Technologies 1200 Series), sample injects $3 \mu \mathrm{ml}$, maintained at 300C. The extract was eluted with mobile phase (HCN 5\%, DI water $95 \%$ with $0.1 \%$ formic acid) at a flow rate of $0.5 \mathrm{~mL} / \mathrm{min}$, run time 10 minutes. The absorbance of the eluant was measured at $254 \mathrm{~nm}$ and concentrations were determined against ascorbic acid standards (Mallinckrodt Baker, Inc., Phillipsburg).

\section{Total Phenolic Compounds}

The method of Singleton and Rossi was used to determine total phenolic compounds [15]. Briefly, freeze-dried samples (50mg) extracted were with $10 \mathrm{~mL} 80 \%$ methanol and shaken at $240 \mathrm{rpm}$ for $16 \mathrm{~h}$. After filtering $50 \mu \mathrm{L}$ of the methanolic extract was then mixed with $350 \mu \mathrm{L}$ of $\mathrm{H} 2 \mathrm{O}$ and $200 \mu \mathrm{L}$ of $1 \mathrm{~N}$ Folin- Ciocalteu reagents (Sigma Chemical Co., St. Louis, Mo). The mixture was incubated for $1 \mathrm{~h}$ in $1.0 \mathrm{~mL}$ of $10 \% \mathrm{Na} 2 \mathrm{CO} 3$ at 250C. The absorbance of the incubated mixture was then measured at $735 \mathrm{~nm}$ a UV-5000 VIS NIR spectrophotometer (Varian Technologies, Australia) with a standard curve to estimate gallic acid (Sigma Chemical Co., St. Louis, Mo.) equivalent (GAE) concentrations.

\section{Anthocyanin Analysis}

Freeze-dried samples (30mg) were extracted with $5 \mathrm{~mL} 2 \%$ $\mathrm{HCl}$ in methanol for $36 \mathrm{~h}$. The liquid extract was separated by centrifugation at $1446 \times \mathrm{g}$ for $15 \mathrm{~min}$. For each sample, separate $400 \mu \mathrm{l}$ aliquots of extract were diluted to $2.0 \mathrm{~mL}$ with two different buffer solutions: potassium chloride buffer $(0.025, \mathrm{pH} 1.0)$ and sodium acetate buffer $(0.4 \mathrm{M}, \mathrm{pH} 4.5)$. After $15 \mathrm{~min}$ reaction, both solutions were filtered $(0.2 \mu \mathrm{m}$ pore size $)$ and the absorbance was measured at $515 \mathrm{~nm}$, where maximum absorption was confirmed in separate scans taken with UV-5000 VIS NIR spectrophotometer (Varian Technologies, Australia) and at $700 \mathrm{~nm}$ for haze correction. Total anthocyanin concentrations were expressed as cyaniding-3glucoside equivalent values, following the protocol described by Giusti and Wrolstad et al. [16].

\section{Total Chlorophylls Content}

Fresh leaf tissue $(100 \mathrm{mg}$ ) was extracted in $5 \mathrm{~mL} \mathrm{~N}, \mathrm{~N}$ dimethylformamide overnight. The absorbance of extraction solution was measured at $647 \mathrm{~nm}$ and 664nm a UV-5000 VIS NIR spectrophotometer (Varian Tech., Australia). Chlorophyll concentration was calculated using the equations described by Moran et al. [17].

\section{Statistical Analysis}

All data were analyzed by one way ANOVA and Duncan's multiple range test (DMRT) using MSTAT at 5\% level of significance.

\section{Results and Discussion}

\section{Effects of Supplemental LED Light Qualities on Growth Characteristics}

Growth characteristics of buckwheat plant were greatly influenced by different supplemental light treatments (Table 1). Plant height, Leaf length, leaf width, and plant fresh weight were increased by supplemental BR light. Far-red light increased the stem length and red light increased the leaf number compared to control. Blue and red lights are the major energy sources for plant growth and development [18]. Previously blue and red lights were proven as an effective lighting source to grow lettuce in a controlled environment [19]. Moreover, the positive effect of red light on the growth of perilla, tomato, chrysanthemum, and various herbs was studied [20]. It is widely understood that phytochrome photoreceptors enhanced the plant growth and development through activation of HY5`s gene which is stimulated by red light [21]. Martinez-Garcia et al. [22] also illustrated that red light activates the phytochrome photoreceptor which enforces the delocalization of the nucleus and modulates gene expression.

Table 1: Effects of supplemental LED light qualities on growth characteristics of buckwheat plants.

\begin{tabular}{|c|c|c|c|c|c|c|c|}
\hline Treatment & Plant Height $(\mathrm{cm})$ & Stem Length (cm) & No. of Node & No. of Leaf & Leaf Length (cm) & Leaf Width $(\mathrm{cm})$ & $\begin{array}{c}\text { Plant Fresh Weight } \\
\text { (g) }\end{array}$ \\
\hline Blue & $27.20 \mathrm{~b}^{\mathrm{z}}$ & $22.10 \mathrm{~b}$ & $2.0 \mathrm{a}$ & $4.30 \mathrm{~b}$ & $4.45 \mathrm{~b}$ & $2.68 \mathrm{c}$ & $2.83 \mathrm{a}$ \\
\hline Red & $25.13 \mathrm{~b}$ & 19.18 c & $2.2 \mathrm{a}$ & $5.10 \mathrm{a}$ & $4.59 \mathrm{~b}$ & $3.23 \mathrm{~b}$ & $2.71 \mathrm{a}$ \\
\hline $\operatorname{BR}(1: 1)$ & $29.65 \mathrm{a}$ & $20.05 \mathrm{c}$ & $2.2 \mathrm{a}$ & $4.70 \mathrm{~b}$ & $5.13 \mathrm{a}$ & $3.55 \mathrm{a}$ & $2.95 \mathrm{a}$ \\
\hline Far red & $29.01 \mathrm{a}$ & $25.06 \mathrm{a}$ & $2.1 \mathrm{a}$ & $3.70 \mathrm{c}$ & $4.21 \mathrm{c}$ & $2.43 \mathrm{c}$ & $1.86 \mathrm{~b}$ \\
\hline Control & $23.70 \mathrm{c}$ & $18.85 d$ & $2.3 \mathrm{a}$ & $3.22 \mathrm{c}$ & $4.10 \mathrm{c}$ & $2.79 \mathrm{c}$ & $1.80 \mathrm{~b}$ \\
\hline
\end{tabular}

z: Mean separation within columns by DMRT at $5 \%$ level 


\section{Effects of Supplemental LED Light Qualities on Phytochemical Contents}

Phytochemicals concentrations in buckwheat were significantly affected by different light treatments (Table 2). Among the treatment BR light significantly increased the ascorbic acid, anthocyanin, phenolic compound of buckwheat plant. Along with BR treatment, B and R treatment also showed good performance compared to control. Total chlorophyll content of buckwheat plants was profoundly increased by BR light treatment. Plant pigments have specific light absorption spectra. For instance; Chlorophyll has high light absorption at 400-500nm [23]. Blue light is abundantly absorbed by photosynthetic pigments and an important catalyst to increase the Chl contents in many plants; including lettuce and cucumber [24].

Table 2: Effects of supplemental LED light qualities on phytochemical contents of buckwheat plants.

\begin{tabular}{|c|c|c|c|c|}
\hline Treatment & Ascorbic Acid $\mathbf{~ m g / 1 0 0 ~ g ~ F W ~}$ & Anthocyanin $\mathbf{~ m g / 1 0 0 ~} \mathbf{g}$ DW & Phenolic Compoundmg GAE $\mathbf{~} \mathbf{g}$ DW & Chlorophyll Content mg/g FW \\
\hline Blue & $200.34 \mathrm{~b}^{\mathrm{z}}$ & $608.23 \mathrm{~b}$ & $710.87 \mathrm{~b}$ & $3.0 \mathrm{a}$ \\
\hline Red & $170.54 \mathrm{bc}$ & $610.71 \mathrm{~b}$ & $711.34 \mathrm{~b}$ & $3.3 \mathrm{a}$ \\
\hline BR $(1: 1)$ & $249.23 \mathrm{a}$ & $686.31 \mathrm{a}$ & $782.36 \mathrm{a}$ & $3.7 \mathrm{a}$ \\
\hline Far red & $187.12 \mathrm{~b}$ & $400.43 \mathrm{~b}$ & $620.10 \mathrm{c}$ & $2.6 \mathrm{~b}$ \\
\hline Control & $100.43 \mathrm{c}$ & $210.15 \mathrm{c}$ & $490.17 \mathrm{~d}$ & $2.1 \mathrm{c}$ \\
\hline
\end{tabular}

z: Mean separation within columns by DMRT at $5 \%$ level, ${ }^{\mathrm{x}} \mathrm{GAE}=$ Gallic Acid Equivalent.

Results from the current study show that buckwheat plants have higher Chl content grown under BR light which is consistent with the findings of Son et al. [19]. Ma et al. [25] illustrated that key gene activity of the enzyme in Chl pigment is stimulated by blue light resulting in higher pigments accumulation. The combination of BR light was an important lighting source for the accumulation of polyphenol compounds such as; anthocyanin, ascorbic acid and total phenolic compound in lettuce [26]. In addition, Son et al. stated that the content of polyphenols in the lettuce increased with the increasing blue light ratio. In our experiment BR light treatment increase the anthocyanin, phenolic compound and ascorbic acid in buckwheat plant support the previous findings [19]. Studies show that blue light is the most effective lighting source to synthesis anthocyanin by stimulating PAL (phenylalanine ammonia-lyase), CHS (chalcone synthesis) and DFR (dihydroflavonol-4-reductase) gene expression [27].

\section{Acknowledgment}

We are grateful to the Rentia Research Group and the Department of Bio health Technology, Kangwon National University.

\section{Author's contributions}

MOKA and MA conceived and designed the experiments and carried out all the experimental works and drafted the final manuscript. JS collected and analyzed the experimental data. CHP and DHC supervised the study and reviewed the final manuscript.

\section{Financial Support}

This research was supported by the Rentia Plant Factory, Chuncheon 24341, Korea.

\section{References}

1. Kozai T, Fujiwara K, Kitaya Y (1994) Modeling, measurement and control in plant tissue culture. Environ Eff their Control Plant Tissue Cult 393: 63-76.

2. Bian ZH, Yang QC, Liu WK (2015) Effects of light quality on the accumulation of phytochemicals in vegetables produced in controlled environments: A review. J Sci Food Agric 95(5): 869-877.
3. Chang CL, Chang KP (2014) The growth response of leaf lettuce at different stages to multiple wavelength-band light-emitting diode lighting. Sci Hortic (Amsterdam) 179: 78-84.

4. Terashima I, Fujita T, Inoue T, Chow WS, Oguchi R (2009) Green light drives leaf photosynthesis more efficiently than red light in strong white light: Revisiting the enigmatic question of why leaves are green. Plant cell Physiol 50(4): 684-697.

5. Brown CS, Schuerger AC, Sager JC (1995) Growth and photomorphogenesis of pepper plants under red light-emitting diodes with supplemental blue or far-red lighting. J Am Soc Hortic Sci 120(5): 808-813.

6. Parks BM, Folta KM, Spalding EP (2001) Photocontrol of stem growth. Curr Opin Plant Biol 4(5): 436-440.

7. Matsuda R, Ohashi Kaneko K, Fujiwara K, Goto E, Kurata K (2004) Photosynthetic characteristics of rice leaves grown under red light with or without supplemental blue light. Plant Cell Physiol 45(12): 18701874.

8. Macedo AF, Leal Costa MV, Tavares ES, Lage CLS, Esquibel MA (2011) The effect of light quality on leaf production and development of in vitrocultured plants of Alternanthera brasiliana Kuntze. Environ Exp Bot $70(1): 43-50$.

9. Schaxov AA (1993) Photoenergetics of plants and harvest (en ruso).

10. Kopsell DA, Kopsell DE (2008) Genetic and environmental factors affecting plant lutein/zeaxanthin. Agro Food Ind Hi-Tech 19: 44-46.

11. Giliberto L, Perrotta G, Pallara P, Weller JL, Fraser PD, et al. (2005) Manipulation of the blue light photoreceptor cryptochrome 2 in tomato affects vegetative development, flowering time, and fruit antioxidant content. Plant Physiol 137: 199-208.

12. Ramalho JC, Marques NC, Semedo JN, Matos MC, Quartin VL (2002) Photosynthetic performance and pigment composition of leaves from two tropical species is determined by light quality. Plant Biol 4(1): 112120 .

13. Alokam S, Chinnappa CC, Reid DM (2002) Red/far-red light mediated stem elongation and anthocyanin accumulation in Stellaria longipes: differential response of alpine and prairie ecotypes. Can J Bot 80(1): 7281.

14. Gahler S, Otto K, Böhm V (2003) Alterations of vitamin C, total phenolics, and antioxidant capacity as affected by processing tomatoes to different products. J Agric Food Chem 51(27): 7962-7968.

15. Singleton VL, Rossi JA (1965) Colorimetry of total phenolics with 
phosphomolybdic-phosphotungstic acid reagents. Am J Enol Vitic 16: 144-158.

16. Durst RW, Wrolstad RE (2005) Unit F1. 2: Characterization and measurement of anthocyanins by UV-visible spectroscopy. Handb Anal food Chem p. 33-45.

17. Moran R (1982) Formulae for determination of chlorophyllous pigments extracted with N, N-dimethylformamide. Plant Physiol 69(6): 13761381.

18. Kasajima S, Inoue N, Mahmud R, Kato M (2008) Developmental responses of wheat cv. Norin 61 to fluence rate of green light. Plant Prod Sci 11(1): 76-81.

19. Son KH, Oh MM (2013) Leaf shape, growth, and antioxidant phenolic compounds of two lettuce cultivars grown under various combinations of blue and red light-emitting diodes. Hort Science 48(8): 988-995.

20. Heo JW, Kang DH, Bang HS, Hong SG, Chun CH, et al. (2012) Early growth, pigmentation, protein content, and phenylalanine ammonia-lyase activity of red curled lettuces grown under different lighting conditions. Korean J Hortic Sci Technol 30(1): 6-12.

21. Quail PH (2002) Photosensory perception and signalling in plant cells: new paradigms? Curr. Opin. Cell Biol 14(2): 180-188.

ISSN: 2574-1241

DOI: 10.26717/BJSTR.2019.13.002467

Cheol Ho Park. Biomed J Sci \& Tech Res

This work is licensed under Creative

Commons Attribution 4.0 License

Submission Link: https://biomedres.us/submit-manuscript.php
22. Martínez García JF, Huq Em Quail PH (2000) Direct targeting of light signals to a promoter element-bound transcription factor. Science 288(5467): 859-863.

23. Lin KH, Huang MY, Huang WD, Hsu MH, Yang ZW, et al. (2013) The effects of red, blue, and white light-emitting diodes on the growth, development, and edible quality of hydroponically grown lettuce (Lactuca sativa L. var. capitata). Sci. Hortic. (Amsterdam)150: 86-91.

24. Hogewoning SW, Trouwborst G, Maljaars H, Poorter H, van Ieperen W, et al. (2010) Blue light dose-responses of leaf photosynthesis, morphology, and chemical composition of Cucumis sativus grown under different combinations of red and blue light. J Exp Bot 61(11): 3107-3117.

25. Ma G, Zhang L, Kato M, Yamawaki K, Kiriiwa Y, et al. (2011) Effect of blue and red LED light irradiation on $\beta$-cryptoxanthin accumulation in the flavedo of citrus fruits. J Agric Food Chem 60(1): 197-201.

26. Johkan M, Shoji K, Goto F, Hashida S, Yoshihara T (2010) Blue lightemitting diode light irradiation of seedlings improves seedling quality and growth after transplanting in red leaf lettuce. Hort Science 45(12): 1809-1814.

27. Meng X, Xing T, Wang X (2004) The role of light in the regulation of anthocyanin accumulation in Gerbera hybrida. Plant Growth Regul 44: 243.

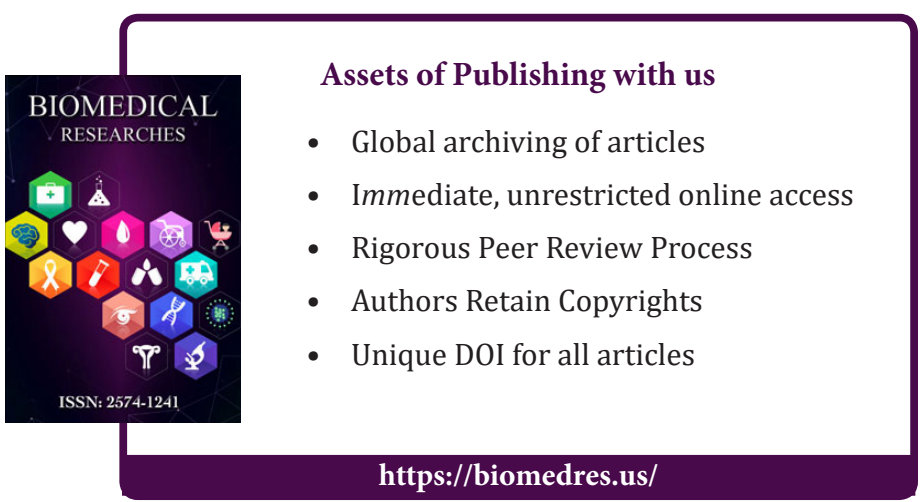

